\title{
Unlocking the Effect of Trivalent Metal Doping in
}

\section{All-inorganic $\mathrm{CsPbBr}_{3}$ Perovskite}

Jun Yin, ${ }^{1}$ Ghada H. Ahmed, ${ }^{1}$ Osman M. Bakr, ${ }^{1}$ Jean-Luc Brédas, ${ }^{2,}{ }^{*}$ Omar F. Mohammed ${ }^{1, *}$

${ }^{1}$ Division of Physical Science and Engineering, King Abdullah University of Science and Technology, Thuwal 23955-6900, Kingdom of Saudi Arabia

${ }^{2}$ School of Chemistry and Biochemistry, Center for Organic Photonics and Electronics (COPE), Georgia Institute of Technology, Atlanta, Georgia 30332-0400, United States

\section{Corresponding Author}

omar.abdelsaboor@kaust.edu.sa; jean-luc.bredas@chemistry.gatech.edu 


\section{ABSTRACT}

Metal-ion doping is one of the most efficient approaches to precisely control the electronic and optical properties of perovskite nanocrystals (NCs). However, the origin of the dramatic contrast in the photoluminescence (PL) behavior of $\mathrm{CsPbBr}_{3} \mathrm{NCs}$ incorporating bismuth $\left(\mathrm{Bi}^{3+}\right)$ and cerium $\left(\mathrm{Ce}^{3+}\right)$ ion dopants remains unclear. Here, we demonstrate dominant PL quenching/enhancing centers both in the bulk and on the surface of $\mathrm{Bi}^{3+} / \mathrm{Ce}^{3+}$ doped $\mathrm{CsPbBr} 3$ by calculating the dopant defect formation energies and charge-transition levels using high-level density functional theory (DFT). We show that the $\mathrm{Bi}^{3+}$ dopants introduce deep trap-states (antisite $\mathrm{Bi}_{\mathrm{Pb}}$ and interstitial $\mathrm{Bi}_{\mathrm{i}}$ ) that are responsible for PL quenching. In sharp contrast, the $\mathrm{Ce}^{3+}$ dopants enhance the $\mathrm{CsPbBr}_{3}$ lattice order and enrich the conduction band-edge states through antisite $\mathrm{Ce}_{\mathrm{Pb}}$, causing PL enhancement. Our findings not only provide new physical insights into the mechanism of the trivalent metal-ion doping effect, but also suggest a new strategy to control the dopant defect states for improving the optical performance of perovskite nanocrystals.

\section{TOC GRAPHICS}

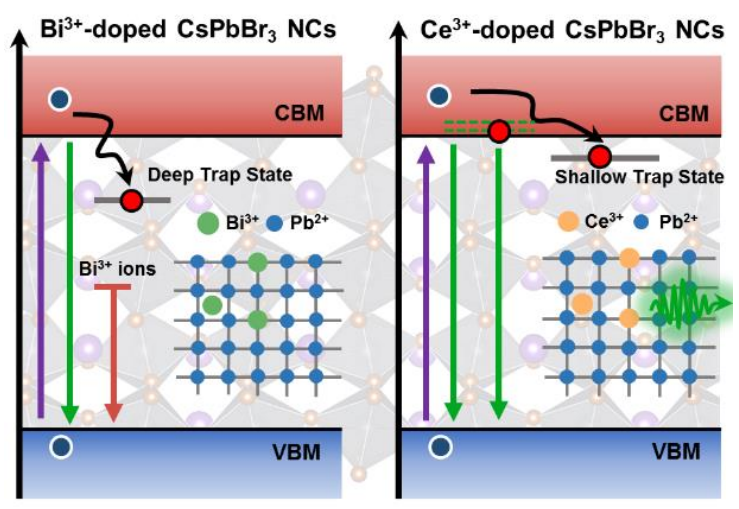


Three-dimensional (3D) inorganic perovskite nanocrystals (NCs) have been considered as nextgeneration semiconducting materials for light-emitting diodes (LEDs), lasers, scintillators, and spintronic devices. ${ }^{1-7}$ The potential industrial applications of 3D perovskite NCs are mainly due to their facile synthesis and attractive optoelectronic properties, such as narrow-band emission, tunable luminescence over the entire UV-visible-near IR spectral region, and high photoluminescence quantum yield (PLQY) ${ }^{8-12}$ The most intensively investigated inorganic perovskites, $\mathrm{CsPbX}_{3}\left(\mathrm{X}=\mathrm{Cl}^{-}, \mathrm{Br}^{-}\right.$, or I') NCs, exhibit remarkable $\mathrm{PLQY},{ }^{13}$ but synthesis strategies are needed to not only improve surface stability and charge carrier mobility but also to precisely engineer the electronic structure and interface for optoelectronic applications. For example, ligand modifications using short organic cations have been proposed as an effective way to passivate the surface uncoordinated $\mathrm{Pb}$ atoms ${ }^{2}$ and introduce more halogen atoms to fill the vacancies. ${ }^{14}$ Metalion doping has also been considered as another promising avenue to control the electronic properties and optical performance of $\mathrm{CsPbX}_{3} \mathrm{NCs}^{15-17}$

In the literature, a variety of dopants, including transition metals $\left(\mathrm{Mn}^{2+}, \mathrm{Cu}^{2+}, \mathrm{Cd}^{2+}, \mathrm{Y}^{2+}\right)^{18-22}$, metalloids $\left(\mathrm{Sn}^{2+}, \mathrm{Bi}^{3+}\right)^{23}$, and lanthanides $\left(\mathrm{Ce}^{3+}, \mathrm{Eu}^{3+}, \mathrm{Yb}^{3+}\right)^{24-26}$, have been incorporated to improve the optical properties of $\mathrm{CsPBX}_{3} \mathrm{NCs}$ due to the intrinsic ionic character and flexibility of the perovskite crystal structure. However, doping-related studies have rarely met the expectation that metal doping improves the photoluminescence efficiency of $\mathrm{CsPbX}_{3} \mathrm{NCs}$, for reasons related to the quenching effects created by the appearance of trap states in the bandgap of the host $\mathrm{CsPbX}_{3}$ NCs. ${ }^{16}$ For example, we reported that doping of $\mathrm{Bi}^{3+}$ ions into $\mathrm{CsPbr}_{3}$ perovskite nanocrystals (NCs) quenches the photoluminescence quantum yield from $78 \%$ to $8 \% .{ }^{23}$ Snaith and co-workers found that $\mathrm{Bi}^{3+}$-doped $\mathrm{MAPbBr}_{3}$ single crystals $(\mathrm{SCs})$ have increased electronic disorder and reduced carrier lifetime and PL intensity, which were attributed to the increase in nonradiative 
recombination centers. ${ }^{27}$ Based on these studies, Kanemitsu and co-workers showed that $\mathrm{Bi}^{3+}$ doping causes no significant changes in the band gap energy of $\mathrm{MAPbBr}_{3} \mathrm{SCs}$ but leads to an enhanced Urbach tail. ${ }^{28}$ Miyasaka and co-workers have also demonstrated that the band gap of Bidoped $\mathrm{CsPbBr}_{3} \mathrm{SCs}$ is comparable to their un-doped case; also, they found that $\mathrm{Bi}^{3+}$ doping causes no changes in the valence band structure, but an increase in the Fermi level of $0.6 \mathrm{eV}$ is observed. ${ }^{29}$ Hence, the decrease in $\mathrm{PL}$ intensity suggests that $\mathrm{Bi}^{3+}$ ions are incorporated into the $\mathrm{CsPbBr}_{3}$ host lattice and create the bulk/surface trap states. In sharp contrast, Yao and co-workers incorporated lanthanide $\mathrm{Ce}^{3+}$ dopants into the $\mathrm{CsPBr}_{3} \mathrm{NCs}$ lattice and achieved a significant enhancement in PLQY of up to $89 \%$ through increasing the dopant concentration ${ }^{24}$ In addition, Song and coworkers confirmed that $\mathrm{Ce}^{3+}$ ion-doped $\mathrm{CsPbCl}_{x} \mathrm{Br}_{3-\mathrm{x}} \mathrm{NCs}$ possess stable blue and green PL. ${ }^{30}$

Here, we followed previously reported doping strategies with some modifications to obtain $\mathrm{Bi}^{3+}$ and $\mathrm{Ce}^{3+}$-doped $\mathrm{CsPbBr}_{3}$ nanocrystals $(\mathrm{NCs})^{23-24}$ and measured their steady-state absorption and PL spectra before and after metal-ion doping at the same dopant concentrations (see the details in the Experimental section of the Supporting Information). As shown in Figure S1, in the case of $\mathrm{Bi}^{3+}$-doped $\mathrm{CsPbBr}_{3} \mathrm{NCs}$, the first excitonic peak in the absorption spectra is very slightly shifted to higher energy, and the PL intensity gradually decreases with increasing $\mathrm{Bi}^{3+}$ dopant concentration. However, in the $\mathrm{Ce}^{3+}$-doping case, the first excitonic peak exhibits a spectral blue shift as the dopant concentration increases, indicating effective incorporation of the metal ions inside the lattice, whereas the PL intensity is notably enhanced. This distinct PL behavior after $\mathrm{Bi}^{3+}$ and $\mathrm{Ce}^{3+}$ doping motivated us to uncover the underlying mechanism by which $\mathrm{Bi}^{3+}$ and $\mathrm{Ce}^{3+}$ ion doping affects the optical properties of $\mathrm{CsPbr}_{3} \mathrm{NCs}$ using high-level density functional theory (DFT) calculations. Our results allow us to demonstrate how the dopants govern the electronic structures of $\mathrm{CsPbBr}_{3} \mathrm{NCs}$ and subsequently influence their optical properties. We also uncover 
the mechanism for the dominant PL quenching and enhancing centers upon $\mathrm{Bi}^{3+}$ and $\mathrm{Ce}^{3+}$ doping, respectively, both in the bulk and on the surface of $\mathrm{CsPbBr}_{3} \mathrm{NCs}$.
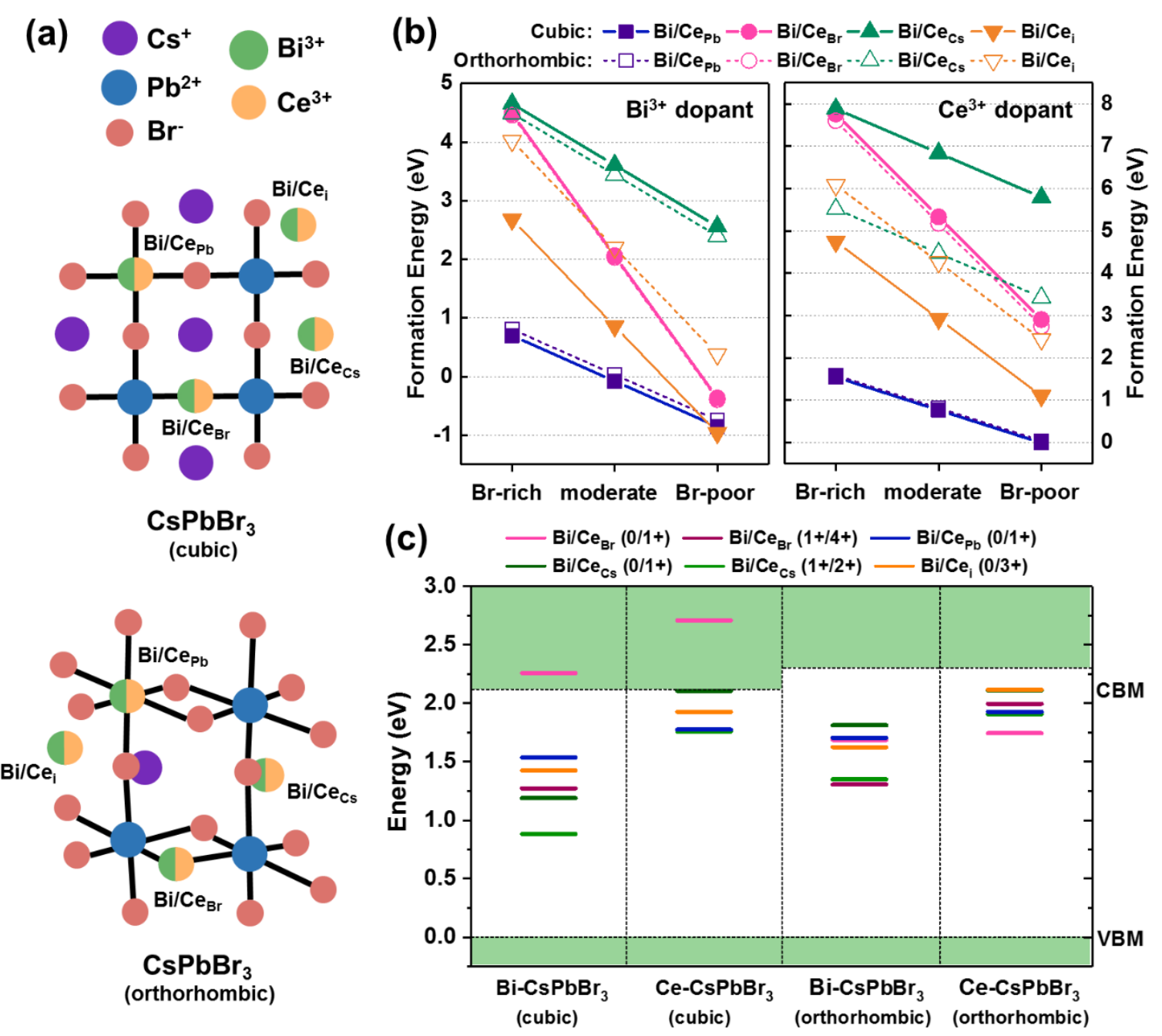

Figure 1. (a) Illustrations of the crystal structures of cubic- and orthorhombic-phase $\mathrm{CsPbBr}_{3}$ with $\mathrm{Bi}^{3+}$ and $\mathrm{Ce}^{3+}$ dopants at $\mathrm{Cs}, \mathrm{Pb}$, and $\mathrm{Br}$ sites $\left(\mathrm{Bi} / \mathrm{Ce}_{\mathrm{Cs}}, \mathrm{Bi} / \mathrm{Ce} \mathrm{Pb}\right.$, and $\left.\mathrm{Bi} / \mathrm{Ce}_{\mathrm{Br}}\right)$ and with $\mathrm{Bi}^{3+}$ and $\mathrm{Ce}^{3+}$ interstitials $\left(\mathrm{Bi} / \mathrm{Ce}_{\mathrm{i}}\right)$; (b) calculated doping formation energies; and (c) doping chargetransition levels for $\mathrm{Bi} / \mathrm{Ce}_{\mathrm{Cs}}, \mathrm{Bi} / \mathrm{Ce}_{\mathrm{Pb}}, \mathrm{Bi} / \mathrm{Ce}_{\mathrm{Br}}$, and $\mathrm{Bi} / \mathrm{Ce}_{\mathrm{i}}$ in cubic- and orthorhombic-phase $\mathrm{CsPbBr}_{3}$ calculated at the HSE+SOC level of theory. 
To understand the $\mathrm{Bi}^{3+}$ and $\mathrm{Ce}^{3+}$ doping effects in the $\mathrm{CsPbBr}_{3}$ bulk, we consider three different dopant antisites $\left(\mathrm{Bi} / \mathrm{Ce}_{\mathrm{Cs}}, \mathrm{Bi} / \mathrm{Ce}_{\mathrm{Pb}}\right.$, and $\left.\mathrm{Bi} / \mathrm{Ce}_{\mathrm{Br}}\right)$ as well as dopant interstitials $\left(\mathrm{Bi} / \mathrm{Ce}_{\mathrm{i}}\right)$, in both cubic and orthorhombic phases of $\mathrm{CsPbBr}_{3}$ (see the illustrations in Figure 1a) ${ }^{1,31}$ Here, the dopant formation energies were calculated by considering the Heyd-Scuseria-Ernzerhof (HSE) hybrid functional combined with spin-orbit coupling (SOC). The HSE+SOC method is an important tool to obtain accurate electronic structures of halide-lead perovskites containing heavy atoms as it corrects the underestimation of the band gaps evaluated at the PBE+SOC level ${ }^{32-34}$ (see more details in the Computational Methods of the Supporting Information; the thermodynamically stable region over which the dopant formation energies are calculated, is shown in Figure S2).

As shown in Figure $1 b$, for $\mathrm{Bi}^{3+}$-doped $\mathrm{CsPbBr}_{3}$, both $\mathrm{Bi}_{\mathrm{Cs}}$ and $\mathrm{Bi}_{\mathrm{Br}}$ antisites have much larger formation energies than $\mathrm{Bi}$ pb, especially under $\mathrm{Br}$-rich and moderate conditions, indicating that the $\mathrm{Bi}^{3+}$ ion preferentially occupies the $\mathrm{Pb}^{2+}$ ion position inside the $\mathrm{CsPbB}_{3}$ lattice as they have similar ionic radii $\left(\mathrm{Pb}^{2+}: 119 \mathrm{ppm} v s . \mathrm{Bi}^{3+}: 117 \mathrm{ppm}\right)$ and metal-halide bond lengths ( $\mathrm{Pb}-\mathrm{Br}: 3.00 \AA$ $\mathrm{vs.} \mathrm{Bi-}$ Br: $2.93 \AA$ ). This finding agrees well with a previous theoretical study of $\mathrm{Bi}^{3+}$-doped $\mathrm{MAPbI}_{3}$, which demonstrated that $\mathrm{Bipb}$ is the dominant defect with a deep transition level. ${ }^{35}$ Interestingly, interstitial $\mathrm{Bi}_{\mathrm{i}}$ is also expected to form in the $\mathrm{CsPbBr}_{3}$ host lattice due to its much lower formation energy under $\mathrm{Br}$-poor conditions. This behavior suggests that interstitial $\mathrm{Bi}_{\mathrm{i}}$ is mainly responsible for the experimentally observed $\mathrm{Bi}^{3+}$ ion emission in the near-infrared spectral range. ${ }^{36}$

In the case of $\mathrm{Ce}^{3+}$ doping, $\mathrm{Ce}_{\mathrm{Pb}}$ has also a much smaller formation energy than the other two antisites (less than $2 \mathrm{eV}$ regardless of the growth condition), indicating that $\mathrm{Ce}^{3+}$ dopants can be incorporated to form $\mathrm{Ce}_{\mathrm{Pb}}$ states with Ce- $\mathrm{Br}$ bond lengths of $2.93 \AA$ in the bulk $\mathrm{CsPbBr}_{3}$ lattice. The probability of forming interstitial $\mathrm{Ce}_{\mathrm{i}}$ in $\mathrm{Cs}_{\mathrm{PbBr}}$ increases as we move from $\mathrm{Br}$-rich to $\mathrm{Br}$ poor conditions, and $\mathrm{Ce}_{\mathrm{i}}$ becomes the dominant dopant defect in $\mathrm{Br}$-poor conditions. 
In addition, we find that $\mathrm{Bi} / \mathrm{Ce} \mathrm{Pb}$ and $\mathrm{Bi} / \mathrm{Ce}_{\mathrm{Br}}$ have almost the same formation energies in the cubic and orthorhombic phases, whereas the $\mathrm{Bi} / \mathrm{Ce}_{\mathrm{Cs}}$ and $\mathrm{Bi} / \mathrm{Ce}_{\mathrm{i}}$ formation energies are larger for the cubic phase than the orthorhombic phase since the substitution of $\mathrm{Cs}^{+}$with a dopant ion or the presence of an additional dopant ion would induce a larger change of the octahedral tilting angle in cubic-phase $\mathrm{CsPbBr}_{3}$ compared to the orthorhombic phase. We also note that, while the dopant formation energies calculated at the GGA/PBE level (Figure S3) are larger than those obtained at the HSE+SOC level, the two sets of calculated energies have nearly identical evolutions as a function of growth condition.

The corresponding charge transition levels of these dopant defects are shown in Figure 1c. For $\mathrm{Bi}^{3+}$-doped $\mathrm{CsPbr}_{3}$, most of the considered dopant defects show deep transition levels within the bandgap in both cubic and orthorhombic phases: i) antisite $\mathrm{Bi}_{\mathrm{Pb}}$ has a transition level energy located $0.59 \mathrm{eV}$ below the conduction band minimum $(\mathrm{CBM})$; and $i$ ) interstitial $\mathrm{Bi}_{\mathrm{i}}$ shows a deep transition level at $\sim 0.7$ below the CBM. The shallow transition level associated with $\mathrm{Bi}_{\mathrm{Br}}(0 / 1+)$ and appearing at $\sim 0.2 \mathrm{eV}$ above the $\mathrm{CBM}$ is in fact difficult to generate due to its large formation energy. We recall that deep doping defect levels can act as carrier traps, leading to nonradiative recombination, whereas shallow levels can preserve the bulk electronic structure and do not degrade the optoelectronic properties. ${ }^{37}$ Therefore, the dominant $\mathrm{Bi}_{\mathrm{Pb}}$ and $\mathrm{Bi}_{\mathrm{i}}$ that have the smaller formation energies could become nonradiative centers and capture the excited carriers from the host lattice.

In the $\mathrm{Ce}^{3+}$-doping case, however, the dominant dopant defects $\left(\mathrm{Ce}_{\mathrm{Pb}}\right.$ and $\left.\mathrm{Ce}_{\mathrm{i}}\right)$ have transition levels located $0.2 \mathrm{eV}$ below the CBM and show shallow transition features in both phases. For both $\mathrm{Bi}^{3+}$ - and $\mathrm{Ce}^{3+}$-doped $\mathrm{CsPBr}_{3}$, the other dopant-induced defects with deep transition levels about $0.3 \mathrm{eV}$ below the CBM have very large formation energies and thus are not expected to 
become effective nonradiative recombination channels. Our HSE+SOC calculations suggest that although the $\mathrm{Bi}^{3+}$ - and $\mathrm{Ce}^{3+}$-doped $\mathrm{CsPBBr}_{3} \mathrm{NCs}$ have the same type of dominant dopant defects (i.e., antisite $\mathrm{Bi} / \mathrm{Ce}_{\mathrm{Pb}}$ and interstitial $\mathrm{Bi} / \mathrm{Ce}_{\mathrm{i}}$ ), the photoluminescence properties of $\mathrm{CsPbBr}_{3} \mathrm{NCs}$ are determined by the specific charge transition levels of these dopants as well as the dopant density of states.

(a)
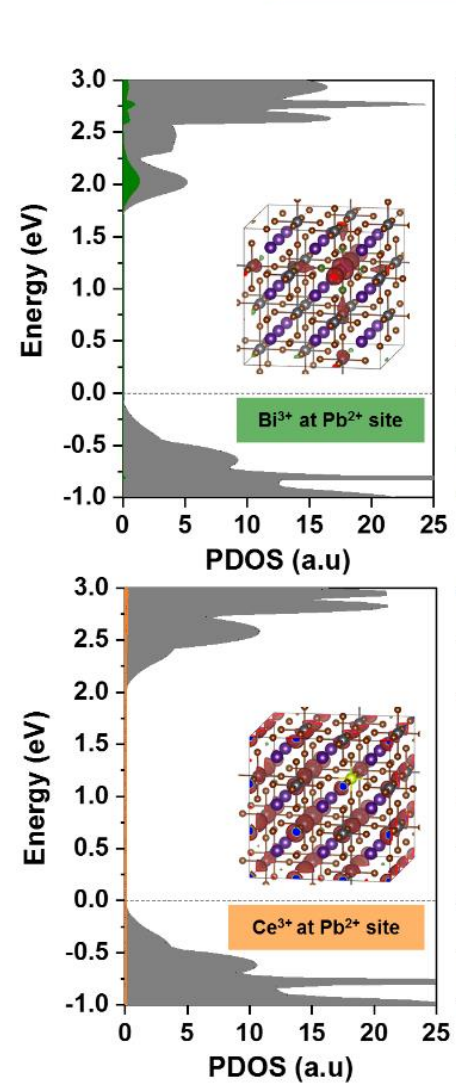

cubic-phase $\mathrm{CsPbBr}_{3}$
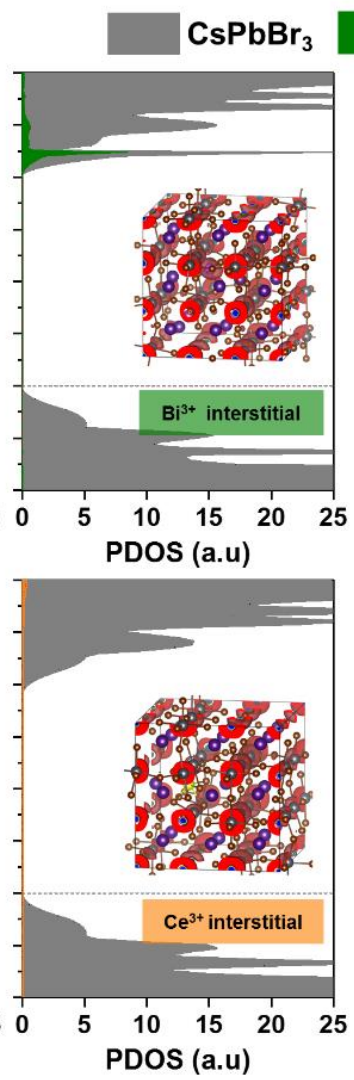

(b) orthorhombic-phase $\mathrm{CsPbBr}_{3}$
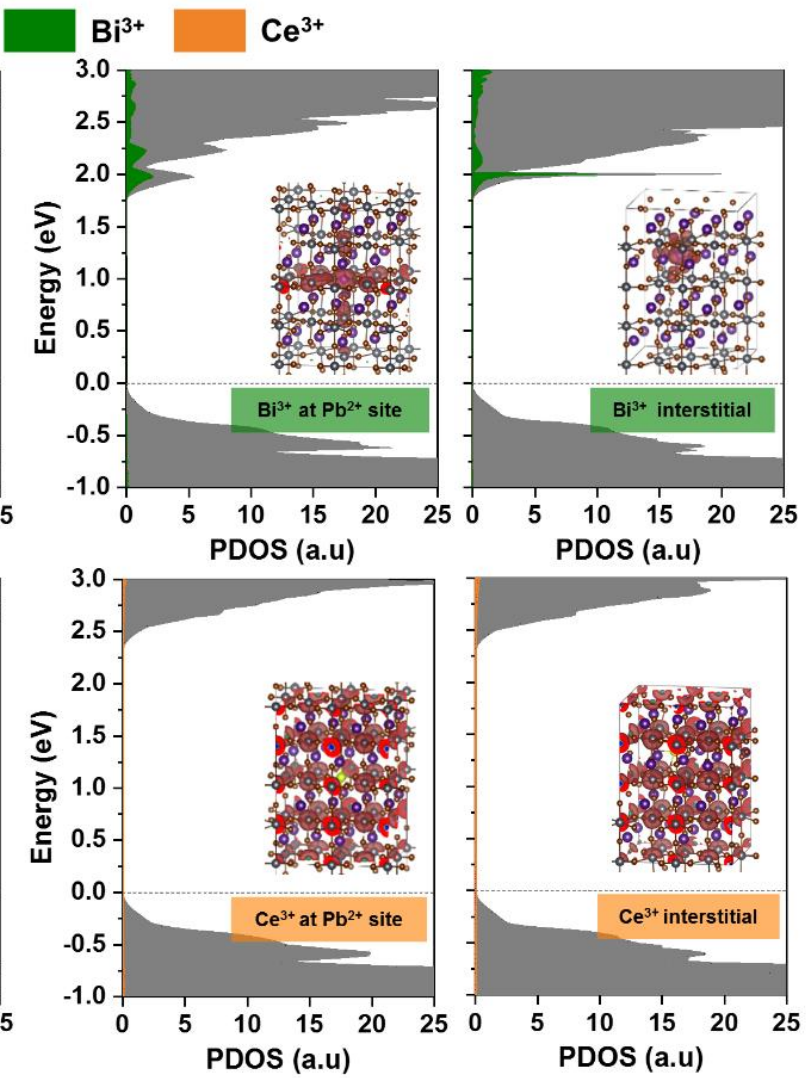

Figure 2. Projected density of states for the $\mathrm{Bi}^{3+} / \mathrm{Ce}^{3+}$ dopants at $\mathrm{Pb}^{2+}$ sites and $\mathrm{Bi}^{3+} / \mathrm{Ce}^{3+}$ interstitial sites in (a) $3 \times 3 \times 3$ cubic-phase and (b) $2 \times 2 \times 2$ orthorhombic-phase $\mathrm{CsPbBr}_{3}$ supercells calculated at the HSE+SOC level of theory. The insets illustrate the electronic charge densities at the CBM after $\mathrm{Bi}^{3+} / \mathrm{Ce}^{3+}$ doping. The valence band maximum is set at zero energy. 
Figure 2 shows the projected density of states (PDOS) for cubic-phase $\mathrm{CsPbBr}_{3}$ after introducing the antisite $\mathrm{Bi} / \mathrm{Ce} \mathrm{Pb}$ and interstitial $\mathrm{Bi} / \mathrm{Ce}_{\mathrm{i}}$ dopants, as calculated at the $\mathrm{HSE}+\mathrm{SOC}$ level of theory. For pristine $\mathrm{CsPbBr}_{3}$, the valence band maximum (VBM) and $\mathrm{CBM}$ of $\mathrm{CsPbBr}_{3}$ are mainly composed of $\mathrm{Br}-4 p, \mathrm{~Pb}-6 s$, and $\mathrm{Pb}-6 p$ orbitals and show delocalized electronic distributions (see Figure $\mathrm{S} 5$ of the Supporting Information). In the case of $\mathrm{Bi}^{3+}$-doped $\mathrm{CsPbBr}$, the appearance of $\mathrm{Bi}_{\mathrm{Pb}}$ shifts the conduction band to lower energy (from $2.16 \mathrm{eV}$ to $1.75 \mathrm{eV}$ ) once the $\mathrm{Pb}^{2+}$ ion is replaced by the $\mathrm{Bi}^{3+}$ dopant and shows a slightly delocalized charge density surrounding the $\mathrm{Bi}^{3+}$ ion at the $\mathrm{CBM}$. Interstitial $\mathrm{Bi}^{3+}$ enriches the conduction band and introduces an additional state at the conduction band edge (located at $\sim 2.1 \mathrm{eV}$ ) as well as a delocalized charge density at the CBM, as $\mathrm{Bi}^{3+}$ ions can be incorporated throughout the $\mathrm{CsPbBr}_{3}$ lattice and lead to orbital hybridization between $\mathrm{Bi}-6 p$ and $\mathrm{Pb}-6 p$ orbitals. This is different from the PDOS of orthorhombic-phase $\mathrm{CsPbBr}_{3}$ which shows a highly localized charge density at the CBM. The same conclusion can be drawn from the PDOS results obtained at the GGA/PBE level of theory (see Figure S6). Unlike the $\mathrm{Bi}^{3+}$-doped case, the band gaps of $\mathrm{CsPBrr}_{3}$ in both phases remain almost unchanged after introducing the $\mathrm{Ce}^{3+}$ dopant at $\mathrm{Pb}^{2+}$ site, and the charge densities for $\mathrm{CBM}$ retain the delocalized feature. Moreover, the interstitial $\mathrm{Ce}^{3+}$ has a small contribution to the conduction band edge in the PDOS of cubic-phase $\mathrm{CsPbr}_{3}$, and the same electronic feature can be found in the orthorhombic case with an interstitial $\mathrm{Ce}^{3+}$. Overall, it can be concluded that the $\mathrm{Bi}^{3+}$ ion can significantly increase the number of defect states and the sub-bandgap density of states; on the other hand, $\mathrm{Ce}^{3+}$ can be doped into $\mathrm{CsPBr}_{3} \mathrm{NCs}$ without introducing additional trap states and can slightly increase the electron density in the conduction band, which modulates the exciton relaxation and recombination of $\mathrm{CsPbBr}_{3} \mathrm{NCs}$. 
(a)

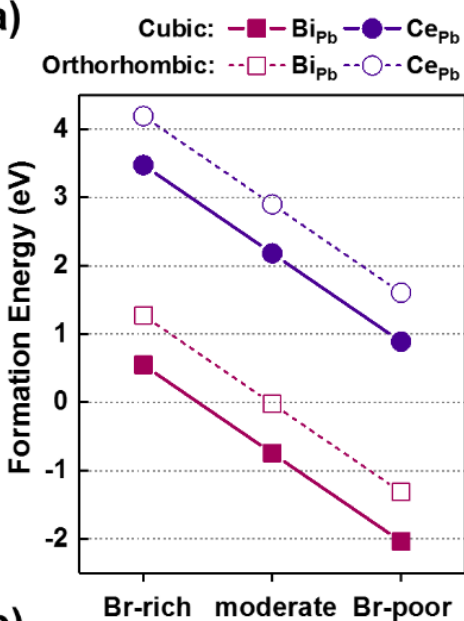

(b)

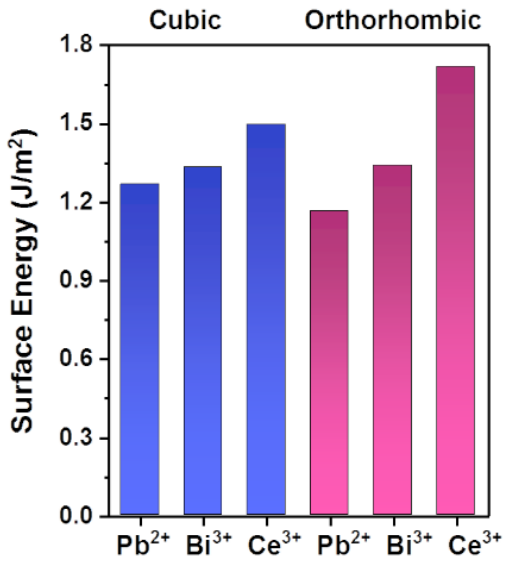

(c)
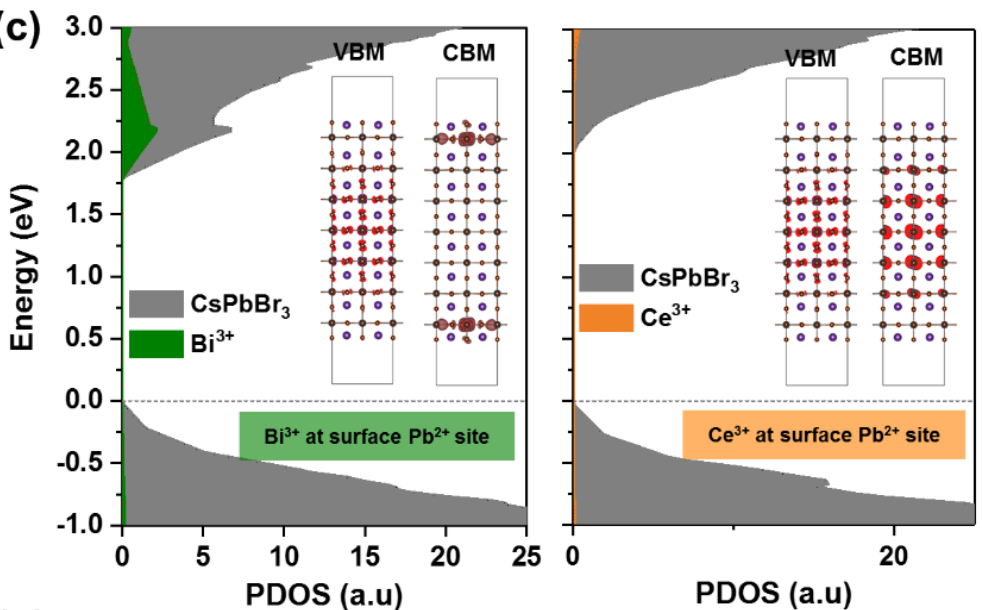

(d)
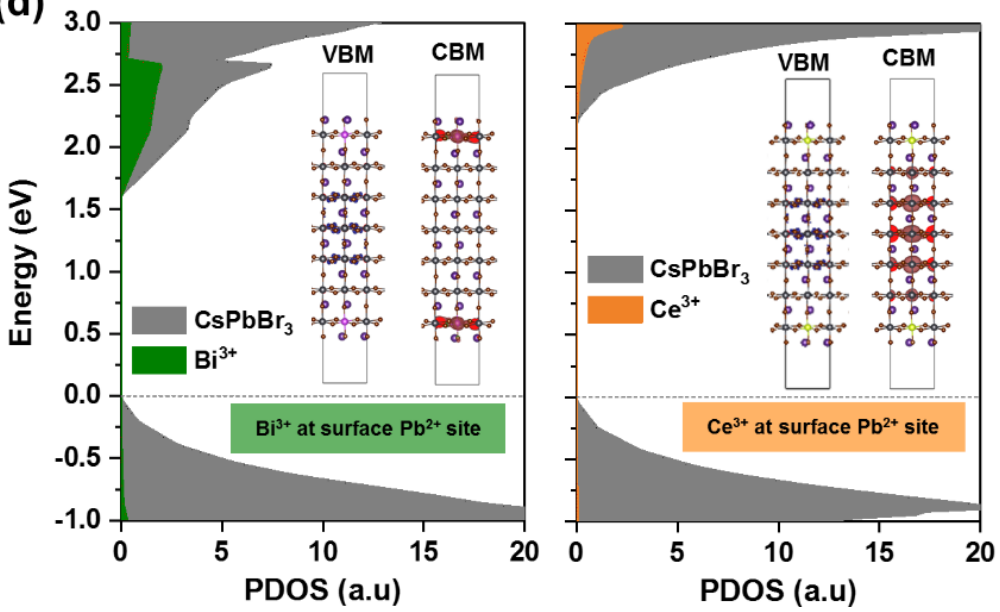

Figure 3. (a) Dopant formation energies for cubic and orthorhombic $\mathrm{CsPbBr} 3$ when $\mathrm{Bi}^{3+}$ and $\mathrm{Ce}^{3+}$ dopants occupy surface $\mathrm{Pb}$ sites $\left(\mathrm{Bi} / \mathrm{Ce}_{\mathrm{Pb}}\right)$. (b) Surface energies for cubic- and orthorhombic$\mathrm{CsPbBr} 3$ slabs with surface $\mathrm{Pb}^{2+}, \mathrm{Bi}^{3+}$, and $\mathrm{Ce}^{3+}$. Projected densities of states for $\mathrm{Bi}^{3+} / \mathrm{Ce}^{3+}$ dopants at surface $\mathrm{Pb}^{2+}$ sites in (c) cubic- and (d) orthorhombic-phase $\mathrm{CsPbBr}_{3}$ slabs, as calculated at the HSE+SOC level. The valence band maximum is set at zero energy. The insets show the electronic charge densities for the valence band minimum (VBM) and conduction band minimum (CBM) after $\mathrm{Bi}^{3+} / \mathrm{Ce}^{3+}$ surface doping.

Although dopants can be successfully incorporated into the bulk $\mathrm{CsPbBr} 3$ lattice, these dopants are also anchored on the surface during the synthesis of $\mathrm{CsPbr}_{3} \mathrm{NCs}$, which can have a significant influence on the optical properties of doped NCs. To consider this scenario, we built slab models 
where $\mathrm{Bi}^{3+}$ or $\mathrm{Ce}^{3+}$ ions occupy the $\mathrm{Pb}^{2+}$ sites and $\mathrm{Br}$ atoms are fully passivated at the top surface (i.e., $\mathrm{PbBr}_{2}$ surface) since the $\mathrm{BiBr}_{3}$ and $\mathrm{CeBr}_{3}$ precursors can bring extra $\mathrm{Br}$ atoms to passivate any uncoordinated $\mathrm{Pb}^{2+}$ atom. As shown in Figures $3 \mathrm{a}$ and $3 \mathrm{~b}$, we find: $i$ ) the formation energies of surface $\mathrm{Bi}$ Pb assume negative values under moderate and $\mathrm{Br}$-poor conditions and are even smaller than those of $\mathrm{Bi} \mathrm{Pb}_{\mathrm{Pb}}$ in the bulk; ii) the surface $\mathrm{Bi}_{\mathrm{Pb}}$ formation energies are much smaller than those of surface $\mathrm{Ce}_{\mathrm{Pb}}$; and $\mathrm{iii}$ ) the surface energies of the $\mathrm{Bi}^{3+}$ slabs are close to those of the pristine $\mathrm{Pb}^{2+}$ slabs, especially in the cubic phase.

These results indicate that $\mathrm{Bi}^{3+}$ dopants can be stabilized on the top surface of cubic-phase $\mathrm{CsPbBr}_{3}$ compared to $\mathrm{Ce}^{3+}$ dopants. For the undoped slabs, both hole and electron distributions are delocalized along the whole slabs (see Figures S5c and S5d of the Supporting Information). Surface replacement with $\mathrm{Bi}^{3+}$ ion leads to the formation of a trap state below the conduction band, as well as a highly localized electron wavefunction on the top surface layers. Similarly to the bulk case, these localized states will act as nonradiative recombination centers for PL quenching. Therefore, although the surface treatment using $\mathrm{BiBr}_{3}$ can provide extra $\mathrm{Br}$ atoms to passivate the uncoordinated $\mathrm{Pb}$ atoms on the surface, the surface $\mathrm{Bi}^{3+}$ dopant can still give rise to a significant number of nonradiative trap states and quench green emission. In sharp contrast, the surface replacement with $\mathrm{Ce}^{3+}$ dopant does not create any new in-gap trap states but instead slightly increases the density of states at the conduction band edge for both cubic and orthorhombic slabs. The deep trap states are also absent in the PDOS calculated at the GGA/PBE level (see Figures S6 and S7), and the band-edge dopant states appear more clearly. Such surface $\mathrm{Ce}^{3+}$ ions can stabilize the $\mathrm{CsPbBr}_{3}$ surface and provide additional electronic states near the conduction band edge, thereby contributing to more emissive channels rather than nonradiative trapping centers. 

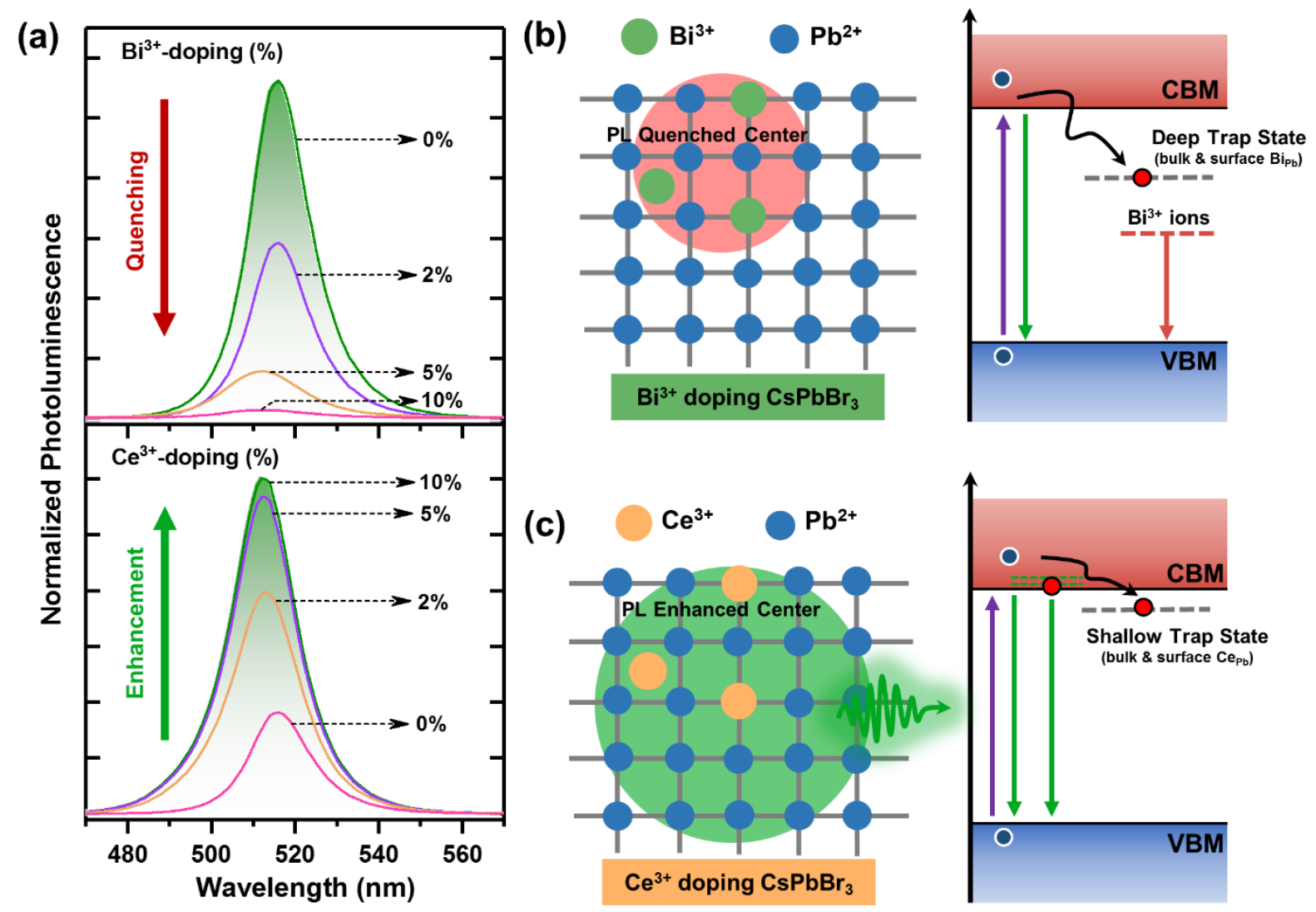

Figure 4. (a) Normalized PL spectra of $\mathrm{CsPbBr}_{3} \mathrm{NCs}$ before and after $\mathrm{Bi}^{3+}$ - and $\mathrm{Ce}^{3+}$-doping at different concentrations $(2 \%, 5 \%$ and $10 \%$, mole percentages). Schematic representation of the proposed doping mechanisms $\left(\mathrm{Bi}^{3+}\right.$ and $\mathrm{Ce}^{3+}$ dopants at $\mathrm{Pb}$ sites and interstitials in the $\mathrm{CsPbBr}_{3}$ bulk, and $\mathrm{Bi}^{3+}$ and $\mathrm{Ce}^{3+}$ dopants on the surface) and energetic diagrams depicting the PL quenching/enhancing process in (b) $\mathrm{Bi}^{3+}$-doped $\mathrm{CsPbBr}_{3}$ and (c) $\mathrm{Ce}^{3+}$-doped $\mathrm{CsPbBr}_{3}$.

According to the PL quenching/enhancing characteristics when using $\mathrm{Bi}^{3+}$ and $\mathrm{Ce}^{3+}$ dopants, as illustrated in Figure 4a, we propose the $\mathrm{Bi}^{3+}$ - and $\mathrm{Ce}^{3+}$-doping mechanisms of $\mathrm{CsPBrr}_{3} \mathrm{NCs}$ depicted in Figures $4 \mathrm{~b}$ and $4 \mathrm{c}$. With excitation above the $\mathrm{CsPbBr}_{3}$ bandgap, electrons are excited from the valence band into the conduction band of $\mathrm{CsPbr}_{3} \mathrm{NCs}$, followed by exciton formation, which can result in near-unity PLQY in such defect-tolerant NCs. However, solution-processed $\mathrm{CsPbBr}_{3} \mathrm{NCs}$ contain many defects, such as $\mathrm{Pb}^{2+}$ and $\mathrm{Br}^{-}$vacancies. Both doping precursors $\left(\mathrm{BiBr}_{3}\right.$ 
and $\mathrm{CeBr}_{3}$ ) play a dual role: $i$ ) dopant ions can occupy $\mathrm{Pb}$ vacancies in the bulk; and $i$ ) additional $\mathrm{Br}^{-}$atoms can fill $\mathrm{Br}^{-}$vacancies in the bulk and terminate uncoordinated surface metal ions. By contrast, in the case of $\mathrm{Bi}^{3+}$-doped $\mathrm{CsPbr}_{3}$, due to the appearance of deep-trap energy levels associated with the dopant defects $\left(\mathrm{Bi}_{\mathrm{Pb}}\right.$ and $\mathrm{Bi}_{\mathrm{i}}$ ) in the bulk and on the surface of the $\mathrm{CsPbr}_{3}$ host, electrons in the conduction band can relax to the deep-trap state and then undergo nonradiative recombination. The photogenerated excitons can also transfer energy to $\mathrm{Bi}^{3+}$ ions with subsequent near-infrared emission. In the $\mathrm{Ce}^{3+}$-doped case, $\mathrm{Ce}^{3+}$ ions can enhance lattice order through host relaxation when they are incorporated into $\mathrm{CsPbr}_{3}$, and they do not create any deep trap states. Our unlocked doping mechanism can also be applied to understand the stability increment using isovalent small ions in hybrid perovskite ${ }^{38}$ and PL enhancement using other lanthanide ions. ${ }^{26}$

In summary, while there has been a large number of reports on the impact of metal-ion doping on the electronic and optical properties of perovskite materials, the mechanism underlying the occurrence of PL quenching in some instances and PL enhancement in others was not fully understood. Here, we have explored and rationalized the opposing effects of doping with the trivalent metals $\mathrm{Bi}^{3+}$ and $\mathrm{Ce}^{3+}$ on the electronic structure and $\mathrm{PL}$ properties of $\mathrm{CsPbBr} 3 \mathrm{NCs}$, using high-level DFT calculations. We have demonstrated that replacing $\mathrm{Pb}^{2+}$ with $\mathrm{Bi}^{3+}$ ions in the bulk or on the surface creates deep trap states that remove the defect-tolerant nature of the host $\mathrm{CsPbr}_{3}$ and function as nonradiative carrier recombination centers. Thus, these defect states act as trapping and scattering centers that significantly quench the PL intensity of the host NCs. By contrast, $\mathrm{Ce}^{3+}$ ions are able to stabilize the bulk/surface structure of $\mathrm{CsPbBr}_{3} \mathrm{NCs}$ and provide band-edge states leading to PL enhancement. Our findings highlight the importance and relevance of bulk/surface 
dopant defects using trivalent metal ions for the optical performance of lead halide perovskites. These results are expected to generalize to other perovskite nanocrystals.

\section{ASSOCIATED CONTENT}

Supporting Information. The Supporting Information is available free of charge on the ACS Publications website.

Experimental and computational methods; crystal lattice parameters of investigated compounds; stability regions and represent active points; dopant defect formation energy and PDOS calculated at the GGA/PBE level.

\section{AUTHOR INFORMATION}

\section{Corresponding Author}

*omar.abdelsaboor@kaust.edu.sa; jean-luc.bredas@.chemistry.gatech.edu

\section{Notes}

The authors declare no competing financial interests.

\section{ACKNOWLEDGMENTS}

This work was supported by King Abdullah University of Science and Technology (KAUST). We acknowledge the Supercomputing Laboratory at KAUST for their computational and storage resources as well as their gracious assistance. The work at Georgia Tech was supported by the Georgia Research Alliance. 


\section{REFERENCES}

(1) Akkerman, Q. A.; Raino, G.; Kovalenko, M. V.; Manna, L. Genesis, Challenges and Opportunities for Colloidal Lead Halide Perovskite Nanocrystals. Nat. Mater. 2018, 17, 394-405. (2) Pan, J.; Shang, Y. Q.; Yin, J.; De Bastiani, M.; Peng, W.; Dursun, I.; Sinatra, L.; El-Zohry, A. M.; Hedhili, M. N.; Emwas, A. H., et al. Bidentate Ligand-Passivated $\mathrm{CsPbI}_{3}$ Perovskite Nanocrystals for Stable near-Unity Photoluminescence Quantum Yield and Efficient Red LightEmitting Diodes. J. Am. Chem. Soc. 2018, 140, 562-565.

(3) Chen, Q. S.; Wu, J.; Ou, X. Y.; Huang, B. L.; Almutlaq, J.; Zhumekenov, A. A.; Guan, X. W.; Han, S. Y.; Liang, L. L.; Yi, Z. G., et al. All-Inorganic Perovskite Nanocrystal Scintillators. Nature 2018, 561, 88-93.

(4) Isarov, M.; Tan, L. Z.; Bodnarchuk, M. I.; Kovalenko, M. V.; Rappe, A. M.; Lifshitz, E. Rashba Effect in a Single Colloidal $\mathrm{CsPbBr}_{3}$ Perovskite Nanocrystal Detected by Magneto-Optical Measurements. Nano Lett. 2017, 17, 5020-5026.

(5) Zhang, X. Y.; Lin, H.; Huang, H.; Reckmeier, C.; Zhang, Y.; Choy, W. C. H.; Rogach, A. L. Enhancing the Brightness of Cesium Lead Halide Perovskite Nanocrystal Based Green LightEmitting Devices through the Interface Engineering with Perfluorinated Lonomer. Nano Lett. 2016, 16, 1415-1420.

(6) Pan, J.; Sarmah, S. P.; Murali, B.; Dursun, I.; Peng, W.; Parida, M. R.; Liu, J.; Sinatra, L.; Alyami, N.; Zhao, C., et al. Air-Stable Surface-Passivated Perovskite Quantum Dots for UltraRobust, Single- and Two-Photon-Induced Amplified Spontaneous Emission. J. Phys. Chem. Lett. 2015, 6, 5027-5033.

(7) Zhang, Y.; Sun, R.; Ou, X.; Fu, K.; Chen, Q.; Ding, Y.; Xu, L.-J.; Liu, L.; Han, Y.; Malko, A. V., et al. Metal Halide Perovskite Nanosheet for X-Ray High-Resolution Scintillation Imaging Screens. ACS Nano 2019, DOI: 10.1021/acsnano.8b09484.

(8) Nedelcu, G.; Protesescu, L.; Yakunin, S.; Bodnarchuk, M. I.; Grotevent, M. J.; Kovalenko, M. V. Fast Anion-Exchange in Highly Luminescent Nanocrystals of Cesium Lead Halide Perovskites $\left(\mathrm{CsPbX}_{3}, \mathrm{X}=\mathrm{Cl}, \mathrm{Br}, \mathrm{I}\right)$. Nano Lett. 2015, 15, 5635-5640.

(9) Akkerman, Q. A.; D'Innocenzo, V.; Accornero, S.; Scarpellini, A.; Petrozza, A.; Prato, M.; Manna, L. Tuning the Optical Properties of Cesium Lead Halide Perovskite Nanocrystals by Anion Exchange Reactions. J. Am. Chem. Soc. 2015, 137, 10276-10281. 
(10) Ahmed, G. H.; Yin, J.; Bose, R.; Sinatra, L.; Alarousu, E.; Yengel, E.; AlYami, N. M.;

Saidaminov, M. I.; Zhang, Y.; Hedhili, M. N., et al. Pyridine-Induced Dimensionality Change in Hybrid Perovskite Nanocrystals. Chem. Mater. 2017, 29, 4393-4400.

(11) Yang, H. Z.; Zhang, Y. H.; Pan, J.; Yin, J.; Bakr, O. M.; Mohammed, O. F. RoomTemperature Engineering of All-Inorganic Perovskite Nanocrsytals with Different Dimensionalities. Chem. Mater. 2017, 29, 8978-8982.

(12) Peng, L. C.; Dutta, A.; Xie, R. G.; Yang, W. S.; Pradhan, N. Dot-Wire-Platelet-Cube: Step Growth and Structural Transformations in $\mathrm{CsPbBr}_{3}$ Perovskite Nanocrystals. ACS Energy Lett. 2018, 3, 2014-2020.

(13) Di Stasio, F.; Christodoulou, S.; Huo, N. J.; Konstantatos, G. Near-Unity Photoluminescence Quantum Yield in $\mathrm{CsPbBr}_{3}$ Nanocrystal Solid-State Films Via Postsynthesis Treatment with Lead Bromide. Chem. Mater. 2017, 29, 7663-7667.

(14) Imran, M.; Caligiuri, V.; Wang, M. J.; Goldoni, L.; Prato, M.; Krahne, R.; De Trizio, L.; Manna, L. Benzoyl Halides as Alternative Precursors for the Colloidal Synthesis of Lead-Based Halide Perovskite Nanocrystals. J. Am. Chem. Soc. 2018, 140, 2656-2664.

(15) Swarnkar, A.; Ravi, V. K.; Nag, A. Beyond Colloidal Cesium Lead Halide Perovskite Nanocrystals: Analogous Metal Halides and Doping. ACS Energy Lett. 2017, 2, 1089-1098.

(16) Swarnkar, A.; Mir, W. J.; Nag, A. Can B-Site Doping or Alloying Improve Thermal- and Phase-Stability of All-Inorganic $\mathrm{CsPbX}_{3}(\mathrm{X}=\mathrm{Cl}, \mathrm{Br}, \mathrm{I})$ Perovskites? ACS Energy Lett. 2018, 3, 286-289.

(17) Zhou, Y.; Chen, J.; Bakr, O. M.; Sun, H. T. Metal-Doped Lead Halide Perovskites: Synthesis, Properties, and Optoelectronic Applications. Chem. Mater. 2018, 30, 6589-6613.

(18) Yong, Z. J.; Guo, S. Q.; Ma, J. P.; Zhang, J. Y.; Li, Z. Y.; Chen, Y. M.; Zhang, B. B.; Zhou, Y.; Shu, J.; Gu, J. L., et al. Doping-Enhanced Short-Range Order of Perovskite Nanocrystals for near-Unity Violet Luminescence Quantum Yield. J. Am. Chem. Soc. 2018, 140, 9942-9951.

(19) Zou, S. H.; Liu, Y. S.; Li, J. H.; Liu, C. P.; Feng, R.; Jiang, F. L.; Li, Y. X.; Song, J. Z.; Zeng, H. B.; Hong, M. C., et al. Stabilizing Cesium Lead Halide Perovskite Lattice through Mn(II) Substitution for Air-Stable Light-Emitting Diodes. J. Am. Chem. Soc. 2017, 139, 11443-11450.

(20) Ahmed, G. H.; El-Demellawi, J. K.; Yin, J.; Pan, J.; Velusamy, D. B.; Hedhili, M. N.; Alarousu, E.; Bakr, O. M.; Alshareef, H. N.; Mohammed, O. F. Giant Photoluminescence 
Enhancement in $\mathrm{CsPbCl}_{3}$ Perovskite Nanocrystals by Simultaneous Dual-Surface Passivation. ACS Energy Lett. 2018, 3, 2301-2307.

(21) Guria, A. K.; Dutta, S. K.; Das Adhikari, S.; Pradhan, N. Doping $\mathrm{Mn}^{2+}$ in Lead Halide Perovskite Nanocrystals: Successes and Challenges. ACS Energy Lett. 2017, 2, 1014-1021.

(22) Das Adhikari, S.; Dutta, A.; Dutta, S. K.; Pradhan, N. Layered Perovskites L $\mathrm{L}_{2}\left(\mathrm{~Pb}_{1-\mathrm{xmn}}\right) \mathrm{Cl}_{4}$ to $\mathrm{Mn}$-Doped $\mathrm{CsPbCl}_{3}$ Perovskite Platelets. ACS Energy Lett. 2018, 3, 1247-1253.

(23) Begum, R.; Parida, M. R.; Abdelhady, A. L.; Murali, B.; Alyami, N. M.; Ahmed, G. H.; Hedhili, M. N.; Bakr, O. M.; Mohammed, O. F. Engineering Interfacial Charge Transfer in $\mathrm{CsPbBr}_{3}$ Perovskite Nanocrystals by Heterovalent Doping. J. Am. Chem. Soc. 2017, 139, 731-737. (24) Yao, J. S.; Ge, J.; Han, B. N.; Wang, K. H.; Yao, H. B.; Yu, H. L.; Li, J. H.; Zhu, B. S.; Song, J. Z.; Chen, C., et al. $\mathrm{Ce}^{3+}$-Doping to Modulate Photoluminescence Kinetics for Efficient $\mathrm{CsPbr}_{3}$ Nanocrystals Based Light-Emitting Diodes. J. Am. Chem. Soc. 2018, 140, 3626-3634.

(25) Milstein, T. J.; Kroupa, D. M.; Gamelin, D. R. Picosecond Quantum Cutting Generates Photoluminescence Quantum Yields over $100 \%$ in Ytterbium-Doped $\mathrm{CsPbCl}_{3}$ Nanocrystals. Nano Lett. 2018, 18, 3792-3799.

(26) Pan, G. C.; Bai, X.; Yang, D. W.; Chen, X.; Jing, P. T.; Qu, S. N.; Zhang, L. J.; Zhou, D. L.; Zhu, J. Y.; Xu, W., et al. Doping Lanthanide into Perovskite Nanocrystals: Highly Improved and Expanded Optical Properties. Nano Lett. 2017, 17, 8005-8011.

(27) Nayak, P. K.; Sendner, M.; Wenger, B.; Wang, Z. P.; Sharma, K.; Ramadan, A. J.; Lovrincic, R.; Pucci, A.; Madhu, P. K.; Snaith, H. J. Impact of $\mathrm{Bi}^{3+}$ Heterovalent Doping in Organic-Inorganic Metal Halide Perovskite Crystals. J. Am. Chem. Soc. 2018, 140, 574-577.

(28) Yamada, Y.; Hoyano, M.; Akashi, R.; Oto, K.; Kanemitsu, Y. Impact of Chemical Doping on Optical Responses in Bismuth-Doped $\mathrm{CH}_{3} \mathrm{NH}_{3} \mathrm{PbBr}_{3}$ Single Crystals: Carrier Lifetime and Photon Recycling. J. Phys. Chem. Lett. 2017, 8, 5798-5803.

(29) Lozhkina, O. A.; Murashkina, A. A.; Shilovskikh, V. V.; Kapitonov, Y. V.; Ryabchuk, V. K.; Emeline, A. V.; Miyasaka, T. Invalidity of Band-Gap Engineering Concept for $\mathrm{Bi}^{3+}$ Heterovalent Doping in $\mathrm{CsPbBr}_{3}$ Halide Perovskite. J. Phys. Chem. Lett. 2018, 9, 5408-5411.

(30) Zhou, D. L.; Liu, D. L.; Pan, G. C.; Chen, X.; Li, D. Y.; Xu, W.; Bai, X.; Song, H. W. Cerium and Ytterbium Codoped Halide Perovskite Quantum Dots: A Novel and Efficient Downconverter for Improving the Performance of Silicon Solar Cells. Adv. Mater. 2017, 29, 1704149. 
(31) Cottingham, P.; Brutchey, R. L. On the Crystal Structure of Colloidally Prepared $\mathrm{CsPbr}_{3}$ Quantum Dots. Chem. Commun. 2016, 52, 5246-5249.

(32) Meggiolaro, D.; De Angelis, F. First-Principles Modeling of Defects in Lead Halide Perovskites: Best Practices and Open Issues. ACS Energy Lett. 2018, 3, 2206-2222.

(33) Meggiolaro, D.; Mosconi, E.; De Angelis, F. Modeling the Interaction of Molecular Iodine with $\mathrm{MAPbI}_{3}$ : A Probe of Lead-Halide Perovskites Defect Chemistry. ACS Energy Lett. 2018, 3, 447-451.

(34) Varley, J. B.; Lordi, V.; Miglio, A.; Hautier, G. Electronic Structure and Defect Properties of $\mathrm{B}_{6} \mathrm{O}$ from Hybrid Functional and Many-Body Perturbation Theory Calculations: A Possible Ambipolar Transparent Conductor. Phys. Rev. B 2014, 90, 045205.

(35) Mosconi, E.; Merabet, B.; Meggiolaro, D.; Zaoui, A.; De Angelis, F. First-Principles Modeling of Bismuth Doping in the $\mathrm{MAPbI}_{3}$ Perovskite. J. Phys. Chem. C 2018, 122, 1410714112.

(36) Zhou, Y.; Yong, Z. J.; Zhang, K. C.; Liu, B. M.; Wang, Z. W.; Hou, J. S.; Fang, Y. Z.; Zhou, Y.; Sun, H. T.; Song, B. Ultrabroad Photoluminescence and Electroluminescence at New Wavelengths from Doped Organometal Halide Perovskites. J. Phys. Chem. Lett. 2016, 7, $2735-$ 2741.

(37) Kang, J.; Wang, L. W. High Defect Tolerance in Lead Halide Perovskite CsPbBr 3 . J. Phys. Chem. Lett. 2017, 8, 489-493.

(38) Saidaminov, M. I.; Kim, J.; Jain, A.; Quintero-Bermudez, R.; Tan, H. R.; Long, G. K.; Tan, F. R.; Johnston, A.; Zhao, Y. C.; Voznyy, O., et al. Suppression of Atomic Vacancies Via Incorporation of Isovalent Small Ions to Increase the Stability of Halide Perovskite Solar Cells in Ambient Air. Nat. Energy 2018, 3, 648-654. 